\title{
INVESTIGACIÓN/RESEARCH
}

\section{CLAVES DEL ÉXITO DEL PERSONAJE PSICÓPATA COMO PROTAGONISTA EN EL CINE}

\author{
Mariona Visa-Barbosa ${ }^{1}$ : Universitat de Lleida. España \\ marionavisa@filcat.udl.cat
}

\section{RESUMEN}

El presente artículo constituye una investigación sobre los personajes de perfil psicópata proliferan en el cine desde hace muchos años. En el presente artículo la intención es realizar una aproximamos a las causas que provocan el éxito de este tipo de películas en la sociedad. Por una parte, se define el carácter psicópata y se exponen algunos ejemplos actuales tanto de la realidad cómo del cine. Finalmente, se analizan los elementos cinematográficos más comunes en las películas sobre psicópatas: la puesta en escena, el casting, la banda sonora, el guión, la curiosidad del espectador, la fascinación de los personajes y la violencia.

PALABRAS CLAVE: Psicópata - Fascinación - Violencia-Cinematografía

\section{THE PSICOPATH AS A MAIN CHARACTER IN CINEMA. KEYS OF SUCCES}

\begin{abstract}
The characters with psychopath profile proliferate in the cinema for many years. In the present article we come closer to the reasons of this success. On one hand, the psychopath character is defined and some current examples (from reality and from cinema) are exposed. Finally, the most common cinematographic elements in the movies on psychopaths are analyzed: the mise-en-scene, the casting, the soundtrack, the script, the curiosity of the spectator, the fascination of the characters and the violence.
\end{abstract}

\footnotetext{
${ }^{1}$ Autor correspondiente

Mariona Visa-Barbosa: Profesora investigadora de Comunicación y Periodismo Audiovisuales. Universitat de Lleida. España

Correo: marionavisa@filcat.udl.cat
} 
KEY WORDS: Psychopath - Fascination - Violence- Cinematography.

\section{INTRODUCCIÓN}

El cine se puede concebir de dos formas diferentes. Des del inicio, cuando el año 1895 los hermanos Lumière hicieron la primera proyección pública mostrando la llegada de un tren a la estación, la gran pantalla ha funcionado como un espejo en el que se ha querido mostrar la realidad del momento de manera documental.

Pero también des de muy pronto, George Méliès utilizó el cinematógrafo como teatro en el que poder representar mundos imaginarios y personajes fantásticos. Esta concepción, propagada durante el siglo XX por la industria americana, nos muestra la pantalla cómo una fábrica de sueños. Así, el objetivo de una película es que el espectador se identifique con los personajes que ve proyectados en la pantalla y se olvide, durante una hora y media, de su vida cotidiana.

Estos personajes con los que se busca la identificación, ya sean reales o fantásticos, evolucionan constantemente, siguiendo modas y corrientes sociales. Desde hace décadas, destaca la proliferación de psicópatas en las pantallas cinematográficas de cualquier parte del mundo.

La relación del cine con los psicópatas empieza a partir del año 1960. Anteriormente, durante la época dorada del clasicismo (años 30, 40 y 50 del siglo XX), el cine estaba clasificado en géneros, donde el crimen estaba presente casi exclusivamente en el cine negro y el cine de terror. El género negro, con películas como Scarface (Howard Hawks,1932), El halcón maltés (John Huston, 1941) o otras dirigidas por Fritz Lang, estaban protagonizadas por un gángster que perturbaba la vida de la ciudad, siento siempre capturado y castigado al final. En el género de terror, influenciado por los monstruos creados por el expresionismo alemán de los años 20, el enemigo siempre era un ser fantástico e irreal. Por lo tanto, en el cine clásico, el mal era siempre un fenómeno exterior, ya fuera un monstruo, un elemento natural, una posesión demoníaca o un grupo de gángsteres. Era un malo arquetípico, que aglutinaba todos los males de la época y, cuando al final de la película era capturado, se restablecía el orden y la sociedad quedaba de nuevo plácida y tranquila. En contraposición a estos personajes, el año 1960 Alfred Hitchcock estrena Psicosis. Con esta película, cambia tanto la forma de explicar las historias como los personajes que las protagonizan. El malo ya no es un monstruo ni un malvado exterior, sino que puede ser nuestro agradable y sonriente vecino de al lado. El malvado es próximo a los personajes, es alguien que puede formar parte del hasta entonces estable núcleo familiar. Con Sospecha (1941), La sombra de una duda (1943), La ventana indiscreta (1954), Psicosis (1960) y gran parte de la filmografía hitchcockniana, el terror es más palpable puesto que en la vida real es más probable que seamos atacados por alguien que conocemos que no por un desconocido. Como dice Luis Rojas Marcos "los seres humanos tenemos mayor probabilidad de ser asaltados, maltratados o torturados en nuestro propio hogar, a manos de alguien supuestamente querido, que en ningún otro lugar" (Rojas Marcos, 1995, p 30) 
Con Hitchcock, el intruso destructor que perturba la plácida vida de la comunidad es uno de los integrantes de ésta. A partir de la aparición del cine independiente, a finales de los años 70, los nuevos directores como Martin Scorsese o Stanley Kubrick, no se limitan a percibir el mal como un fenómeno interior, sino que convierten a los malvados en protagonistas absolutos de sus historias. Los protagonistas de Taxi Driver (Martin, 1976), El cabo del miedo (Martin, 1991), La naranja mecánica (Kubrick, 1971) o El resplandor (Stanley, 1980) son personajes de moral dudosa, pero que cuentan con la simpatía del público y, no siempre son castigados y condenados al final de la historia. Este contexto es ideal para la aparición de psicópatas y asesinos en serie como personajes, de los que habitualmente se justifica su maldad, ya sea con una enfermedad mental (caso de Norman Bates de Psicosis y Ed Gein, que sufren esquizofrenia) o con el relato de una infancia plagada de maltratos y familias desestructuradas.

\section{METODOLOGÍA}

El propósito de la presente investigación es realizar un análisis crítico sobre el papel del psicópata en el cine, el impacto y la asiduidad que genera en ciertos públicos mediante el método histórico lógico y la generalización. Del mismo modo a través de estos métodos se logra reflejar la construcción del psicópata como personaje en las películas, definir un conjunto de características esenciales para su éxito en taquilla y para la atracción de audiencia.

Se realiza en primer orden un recorrido histórico, mediante el análisis documental, acerca de los primeros personajes acreditados como psicópatas en la industria del séptimo arte.

\section{ANÁLISIS Y DISCUSIÓN}

\subsection{La personalidad psicópatica}

Pero las películas sobre psicópatas puros son aquellas donde el protagonista mata sin ningún motivo ni remordimiento. Es el malo convertido en el centro absoluto de la historia, sin ningún antagonista con quien luchar, dónde las víctimas no se personalizan. Estamos delante de la abstracción absoluta. Como diría De Quincey, es el asesinato elevado a la categoría de las Bellas Artes.

La definición de psicópata, según Vicente Garrido, es la siguiente:

Este sujeto nos presenta una imagen de una persona preocupada por sí misma, cruel y sin remordimientos, con una carencia profunda de empatía y de la capacidad para formar relaciones cálidas con los demás, una persona que se comporta sin las restricciones que impone la conciencia. Lo que destaca en él es que están ausentes las cualidades esenciales que permiten a los seres humanos vivir en sociedad (Garrido, 2000, p 29) 
Entre las características básicas que definen una personalidad psicopática, encontramos las siguientes: locuacidad, encanto, egocentrismo, falta de remordimientos, falta de empatía, mentira, manipulación, emociones superficiales, impulsividad, necesidad de excitación continuada, deficiente control de la conducta, falta de responsabilidad y conducta antisocial. Parece que no tengan emociones, únicamente intentan imitarlas. Son personas que no saben experimentar ninguna satisfacción perdurable y siempre van más allá para conseguir gratificación en el crimen, en las aventuras sexuales o con el poder. No hay una justificación de porque matan. Normalmente, no abusan del alcohol ni de las drogas, ni provienen de familias desestructuradas. Simplemente matan, a menudo a gente de su entorno, para satisfacer sus impulsos. Es una violencia sin sentido, aterradora. Como definió el psiquiatra francés Philippe Pinel, es como una "locura sin delirio". ${ }^{2}$

Se ha hecho patente que algunos psicópatas (reales o ficticios) comparten el rechazo hacia las mujeres. Esta misoginia los empuja a cometer crímenes únicamente contra el sexo femenino. Los convierten en una clase de castigo contra la lascivia y la sexualidad. Algunos ejemplos los podemos encontrar en los filmes El fotógrafo del pánico (Michell Powell, 1959), Psicosis (Alfred Hitchcock, 1960) o El enemigo de las rubias (Alfred Hitchcock, 1927). Pero Vicente Garrido, en su libro El psicópata, dice que "sería bastante correcto decir que no sabemos lo que causa la psicopatía" (Garrido, 2000, p 60).

En las últimas décadas, hay dos casos que han causado especial conmoción en la opinión pública española, tanto por la atrocidad del acto como por la frialdad con que se ha cometido. El primer caso es el del joven de 16 años, José Rabadán, que el año 2000 mató sus padres y su hermana con una Katana ${ }^{3}$. Hasta aquel momento, el asesino había sido considerado un chico normal, sin ningún problema de conducta. En el momento de ser detenido se mostraba tranquilo, sin remordimientos aparentes y en ningún momento esquivó las cámaras de televisión. Al contrario, parecía buscar los objetivos y disfrutar de los cinco minutos de gloria que, como decía Andy Warhol, todo el mundo puede conseguir.

El segundo casẻ es el que la prensa tituló "Los asesinos del juego de rol". En abril de 1994, dos estudiantes de Madrid mataron a puñaladas a un hombre de 52 años para hacer realidad un juego de rol, y parecían dispuestos a buscar más víctimas si no hubieran sido detenidos. Uno de los asesinos, Javier Rosado, tenía pretensiones literarias y escribió todos los acontecimientos en su diario, que fue publicado en el periódico El País ${ }^{4}$ La narración de los hechos es muy detallada, y se observan muchos rasgos identificadores de la personalidad psicopática.

El hecho mismo de escribir el crimen en un diario, ficcionalizando y alienando un

\footnotetext{
${ }^{2}$ En 1809 el francés Philippe Pinel describió el concepto de 'Locura sin delirio' para designar un patrón de conducta caracterizado por la falta de remordimientos y la ausencia completa de restricciones

${ }^{3}$ Los hechos fueron llevados al cine en el año 2009 en la película dirigida por Ventura Durrall titulada"Las dos vidas de Andrés Rabadán

${ }^{4}$ El País, febrero de 1997
} 
hecho real nos informa del carácter egocéntrico del asesino. En varios momentos se refiere con desprecio a las víctimas que descarta: "Era una víctima potencial casi perfecta. Tenía cara de idiota, apariencia feliz y unas orejas tapadas miedo un walkman. Pero era un tío."

Al cabo de unos instantes, encuentra una chica que hubiera sido ideal si no fuera por la "maldita manía de acompañar a las mujeres a sus casas". Finalmente, encuentran a la que será su víctima y la define así: "Era gordito, rechoncho, con o una cara de alucinado que apetecía golpearla y una papeleta imaginaría que decía: "Quiero morir".

Más tarde, cuando describe el método que utilizó para matarlo, cita una escena de una película: "Se me ocurrió una idea espantosa que jamás volveré a hacer y que saqué de la película Hellraiser. Cuando los cenobitas de la película deseaban que alguien no gritara le metían los dedos en la boca".

Después continúa insultándolo: "Es espantoso lo que tarda en morir un idiota.". Al día siguiente, una vez todo ha pasado, el asesino busca en los periódicos alguna información sobre el crimen y se siento elogiado: " Era una víctima potencial casi perfecta. Tenía cara de idiota, apariencia feliz y unas "La noticia decía que le habian dado seis puñaladas entre lo cuello y el estómago (je je, je)"

Finalmente, demuestra cierta compasión cuando se refiere a la víctima: "Pobre hombre! No merecía lo que le pasó. Fue una desgracia ya que buscábamos adolescentes y no pobres obreros trabajadores. En fin, la vida es muy ruin."

Estos dos ejemplos de casos reales son muy clarificadores de la reacción de un psicópata ante sus crímenes. A la vez, también es una actitud que adoptarán muchos personajes cinematográficos. De hecho, el texto antes citado parece extraído del diálogo de una película sobre asesinos en serie. Pero el personaje, en este caso, es de carne y huesos; fue condenado a 42 años de cárcel.

Desgraciadamente, hay muchos más ejemplos de este tipo de comportamiento y nos es imposible citarlos todos. Pero hay un asesino americano mítico, puesto que el cine ha adaptado su vida, que vale la pena repasar. Su nombre es Ted Bundy. Era el prototipo de buen americano, con estudios y grandes habilidades sociales. Pero fue juzgado el 1989 por haber cometido gran número de violaciones y asesinatos. Como era agradable y despertaba confianza, las chicas no dudaban en ofrecerle ayuda si él pedía que le acompañaran al coche o a casa. Era culto y él mismo se defendía en los juicios, alegando que las lecturas de Sade y la adicción al alcohol le habían trastornado. Los medios de comunicación sucumbieron a la fascinación que despertaba este personaje y le dedicaban grandes espacios. Ted Bundy sabía muy bien cómo aprovecharlos. Desviando la culpabilidad de los crímenes hacia la sociedad que permite la libre circulación de pornografía violenta, se presentaba como víctima. Consciente de que estaba representando un personaje, siempre hablaba de él en tercera persona. 
A pesar de la monstruosidad de sus actos, con su manera de hablar y justificarse atrajo la atención del público. Despertó tanta fascinación en la sociedad que incluso recibió cartas de admiradoras declarándole su amor. Finalmente, fue juzgado y condenado a muerte. En este caso, el horror y la seducción formaban las dos caras de la misma moneda: el psicópata.

Cabe decir que no siempre son personajes criminales de buen principio. Puede que únicamente cometan los crímenes al final de su historia, por evitar que los familiares sepan realmente quienes son. Es el caso de La vida de nadie (Eduard Cortés, 2002) o de la francesa El empleo del tiempo (Laurent Cantet, 2001). Esta última basada en el libro El adversario de Emmanuel Carrère, escrito a partir de un caso real, en el que una persona engaña durante muchos años a su familia y amigos, haciendo creer que tiene un buen trabajo y dinero cuando todo es una farsa.

\subsection{Claves del éxito del personaje psicópata como protagonista en el cine}

¿Por qué estos personajes psicópatas resultan tanto atractivos cuando los vemos ficcionalizados en una película? ¿Hay algún motivo de por qué sentimos esta atracción por el monstruo? Intentaremos aproximarnos a las posibles causas. Analizaremos los elementos cinematográficos comunes en las películas sobre psicópatas, enumerando los factores que permiten realizar películas de gran atractivo y éxito muerte. En este caso, el horror y la seducción formaban las dos caras de la misma moneda: el psicópata.

\subsubsection{La puesta en escena}

En este punto nos interesa tanto la decoración como los complementos del personaje. El carácter dual de los psicópatas, seductores y asesinos a la vez, hacen muy propicias las escenas ante el espejo, con el desdoblamiento o repetición en múltiples fragmentos que esto conlleva. A la vez, el espejo también actúa como elemento narcisista, puesto que aparte del desdoblamiento metafórico, no podemos olvidar la necesidad de gustarse y contemplarse hasta el último detalle que sienten algunos psicópatas. En Ted Bundy (Matthew Bright, 2002), la primera escena nos muestra al protagonista ante el espejo ensayando sus diversas caras e inflexiones de voz, presentándose de muchas formas diferentes: educadamente, insistentemente, terroríficamente. También en Henry, retrato de un asesino (John Mcnaughton, 1986) encontramos la escena del personaje lavándose las manos, con el espejo que nos devuelve su mirada de indiferencia. En El resplandor (Kubrick, 1980), el director grabó numerosas escenas a partir de los reflejos en los espejos, sobre todo cuando la locura del personaje se empieza a hacer patente. De esta manera ya no es él, sino otro (la otra cara de él mismo) quien comete crímenes y es capaz de matar incluso a su propia familia. Tampoco podemos olvidar el protagonista de Taxi Driver (Scorsese, 1976), que mantiene largos monólogos ante del espejo. Al inicio de American Psycho (Harron, 2000), mientras el protagonista se pone crema a la cara, se observa detenidamente en el espejo mientras recita: 
Hay una idea de un tal Patrick Bateman, una especie de abstracción, pero no se mí yo real, sólo una entidad, algo ilusorio. Y aunque puedo ocultar mí fría mirada y puedes darme la mano y sentir el contacto de la carne, y quizá incluso llegas a creer que llevamos estilos de vida parecidos, simplemente, no estoy ahí ${ }^{5}$

Aparte de la utilización del espejo, también destaca la decoración de los espacios propios del protagonista y en especial, la casa, lugar dónde ocurren la mayoría de los crímenes y también las posteriores ocultaciones de los cadáveres. En La naranja mecánica (Stanley Kubrick, 1971), la dirección artística corre a cargo de Russell Hagg. El diseño de los objetos está sumamente cuidado, basado en una estética pop de los años 60. También el vestuario y maquillaje de los actores es especialmente significativo (pestañas postizas, labios rojos), hecho que da un aire de teatralidad y grandilocuencia que ayuda a Alex, el protagonista, a distinguirse del resto de la sociedad. En American Psycho (Mary Harron, 2000), adaptación de la polémica novela de Bret Easton Ellis, el personaje es un yuppie nuevayorqués de los años 80. Su esmerada forma de vestir, la importancia de las marcas, la elección de los mejores restaurantes y el gran número de productos de belleza que utiliza hacen que incluso el diseño de una tarjeta de presentación pueda ser un motivo de envidia, que puede tener consecuencias muy negativas

\subsubsection{El casting}

Es evidente que el peso de este tipo de películas recae en su personaje protagonista. Por lo tanto, la interpretación es un punto clave al que se dedica especial atención. Los actores escogidos para interpretar estos papeles ensayan una serie de trucos, formas de andar, dicciones especiales, gesticulación y miradas que ayudan a hacer más impresionantes y fascinadores a sus personajes. Hay gran número de actores que han interpretado psicópatas: Harvey Keitel, James Woods, Kevin Spacey, Christian Bale, Anthony Hopkins, Eduardo Noriega. De entre todos, destacan dos nombres en el que el personaje y el actor han quedado identificados durante mucho tiempo: Robert de Niro y Jack Nicholson. Son, desde los años 70, los malos por excelencia del cine. La lista de malvados más destacados (no siempre psicópatas) interpretados por parte de Robert de Niro es la siguiente: Taxi Driver (Scorsese,1976), El cazador (Cimino, 1978), Los intocables de Elliot Ness (Brian de Palma, 1987), El cabo del miedo (Scorsese, 1991), Uno de los nuestros (Scorsese, 1990). Por parte de Jack Nicholson Alguien voló sobre el nido del cuco (Milos Forman, 1975), El resplandor (Kubrick, 1980), Batman (Tim Burton, 1989). En el rostro de estos dos actores se dibuja la mirada de la locura psicótica como en ninguna otra, a la vez que despiertan gran simpatía en el patio de butacas. Son malos con nombre propio, con matices y evoluciones. Con ellos dos, el malo deja de ser el antagonista superficial que se debe combatir y pasa a ser el protagonista absoluto que cuenta con el apoyo del espectador. Los personajes que interpretan son anti-héroes con los que el espectador se identifica en parte, e incluso se disgusta si al final son capturados.

\footnotetext{
${ }^{5}$ American Phsycho
} 
De hecho, los psicópatas son como actores que se representan a ellos mismos en la vida real. Aparte de ser exhibicionistas y disfrutar siendo lo centro de atracción, actúan en cada momento tal y como se debe hacer. En los juicios y en la cárcel tienen buen comportamiento, son amables y considerados con el resto. También son amables con la prensa, la buscan. Incluso con la sociedad y con el espectador. Àlex, en $L a$ naranja mecánica, se dirige al espectador diciendo "mis únicos amigos". Tienen un sentido de la puesta en escena en su vida real. Albert Desalvo, el auténtico estrangulador de Boston, dejaba siempre las medias con que ahogaba las víctimas alrededor del cuello. También manifestaba sentido del humor puesto que a una de las chicas a las que estranguló le dejó una nota entre los dedos del pie izquierdo en la que decía: "Happy new year". Marcel Petit, un médico que asesinaba a judíos después de engañarlos asegurándolos que los ayudaría a escapar de las fuerzas nazis, hacía broma en el momento de su ejecución. En el momento antes de ser guillotinado, dijo a los testigos: "Caballeros, las ruego que no miren. No va a ser bonito". Los psicópatas son actores en sus propias vidas, por lo tanto, a la hora de adaptarlas al cine es más fácil. Son personas que crean un personaje de ellas mismas y, por lo tanto, el actor que las interpreta se encuentra ya construidas las características básicas.

\subsubsection{La banda sonora}

La banda musical en una película está formada por la música, el diálogo y los efectos sonoros. La música puede ser original, compuesta de forma expresa para el film, o pre- existente. En el caso de las películas que estamos analizando lo más habitual es encontrar música pre-existente, sobre todo música clásica. Los personajes psicópatas acostumbran a ser personas cultas, amantes de la buena música. El Doctor Hannibal Lecter, interpretado por Anthony Hopkins en El silencio de los corderos (Johathan Demme, 1991), hace sonar las Variaciones Goldberg de Bach en su celda mientras mata y devora a los dos policías que le traen la comida. Àlex, de La naranja mecánica (Stanley Kubrick, 1971), es un amante de Ludwig van Bethoven, en particular de la 5a sinfonía. Escucha esta música a todas horas y tiene un gran póster del compositor colgado a su habitación. Pero la mala suerte hace que esta sea la música del experimento Ludovico, con el que quieren corregir su comportamiento asociando artificialmente efectos de náusea al contemplar imágenes desagradables. Como los psicópatas no experimentan sentimientos malos ante el mal, los encargados del experimento intentan provocarlos. A partir de este momento, el personaje será incapaz de escuchar su música preferida.

Con respecto al diálogo, éste se convierte en una herramienta básica para definir al personaje. Seguramente en la más importante, puesto que es la que nos ayuda a ver cómo piensa y qué percepción tiene del mundo que le rodea. Destacan unos rasgos característicos presentes en muchos personajes, que son también definitorios de la personalidad psicopática:

a) Utilizan el lenguaje para decir a la gente lo que quiere escuchar. En Tesis (Alejandro Amenábar 1996), el personaje interpretado por Eduardo Noriega, dice a la hermana de la protagonista: "Hay que ser muy inteligente para estudiar 
derecho". La halaga continuamente porque quiere seducirla

b) Muestran sentimientos en las palabras, aun cuando no los sienten realmente.

c) Son capaces de decir "Te quiero", refiriéndose a la víctima, cuando son entrevistados por la policía o los periodistas.

d)Cinismo y sentido del humor negro. Cuando el protagonista de Tesis, Bosco (Eduardo Noriega) está a punto de matar a la chica que investiga snuff-movies le dice, sin cambiar de cara: "Té cuento un poco lo que vamos a hacer. Primero te voy a golpear la cabeza durante un rato"

e) Hablan de ellos en tercera persona.

f) Son muy sociales, habladores. No despiertan sospechas porque son educados y se dirigen a la gente amablemente.

g) Hablan despectivamente de los otros. En Ocurrió cerca de tu casa (Belvaux \& Bonzel, 1992), unos periodistas realizan un reportaje de video sobre la vida de un psicópata. Este está continuamente despreciándolos y juzgando su trabajo: "Mueves la cámara como quieres", "Tienes aliento de cabra", "Haces cara de idiota.".

h) Hacen chistes que sólo entienden ellos. En American Psycho (Mary Harron, 2000), Patrick Bateman cita a Ed Gein y a Ted Bundy, realizando juegos de palabras macabras que nadie comprende.

i) Egocentrismo. Muy a menudo las películas están narradas en $1^{\mathrm{a}}$ persona, con voz en off del protagonista. Y su ego los delata:"Estábamos yo, y mis tres drugos", dice Àlex de La naranja mecánica (Stanley Kubrick, 1971). En este caso, incluso se usa un lenguaje especial, con vocabulario inventado, para caracterizar más la rareza del personaje

j) Finalmente, igual que hacía el asesino del juego de rol, muestran cierta piedad ante los crímenes que han cometido: "Estas cosas no deberán pasar", dicen en Ocurrió cerca de tu casa (Belvaux \& Bonzel, 1992).

\subsubsection{El guión}

La fuente de estas películas proviene de hechos reales, de la adaptación de obras literarias, o bien de la imaginación de los directores. Los hechos reales son los más abundantes puesto que las noticias protagonizadas por psicópatas causan un gran impacto social, haciéndolas idóneas para adaptaciones cinematográficas. El caso más relevante es el de Ted Bundy, del que ya hemos hablado anteriormente. También hay el caso de Ed Gein, que ha dado lugar a dos películas. La primera, Ted Bundy (Bright, 2000), es una adaptación fiel de la vida de un hombre de EE.UU, que asesinaba y guardaba los cadáveres de sus víctimas, a las que mataba siguiendo órdenes de su difunta madre. Anteriormente, Hitchcock la había adaptado, con variaciones, en Psicosis (Hitchcock 1960). También encontramos los casos de A sangre fría (Richard Brooks, 1967), Doctor Petit (de Chalonge, 1990), Malas tierras (Malick, 1973), Citizen X (Gerolomo, 1995), Henry, retrato de un asesino (McNaughton, 1986).

Las adaptaciones literarias también son importantes. La literatura ha creado muchos personajes psicópatas. Uno de los casos más relevantes, aunque no cuenta con adaptación al cine, es la de El extranjero, de Albert Camus. Narrada en $1^{\circ}$ persona, relata la pasividad y la frialdad con que el protagonista se enfrenta a la muerte de su 
madre y el posterior crimen que comete. Esta novela tuvo un gran éxito y su protagonista se convirtió en un anti-héroe con el que muchos jóvenes se identificaban. Otras novelas que destacan, también de gran éxito e impacto en su aparición son $\mathrm{La}$ naranja mecánica de Anthony Burguess, American Psycho de Bret Easton Ellis y El silencio de los corderos de Thomas Harris. Finalmente, existen historias imaginarias en las que se mezclan rasgos típicos del comportamiento real de los psicópatas con la ficción, dando lugar a escenas de gran voltaje violento, cinismo y teatralidad. Es el caso de Ocurrió cerca de tu casa (Rémy Belvaux y André Bonzel, 1992) o Harry, un amigo que os quiere (Moll 2000) o escenas como la de Reservoir Dogs (Quentin Tarantino, 1992), en la que un personaje corta una oreja y después moja con gasolina a un policía. Este último es un ejemplo de dónde puede llegar la imaginación de un autor cuando el personaje en el que se inspira es un psicópata.

\subsubsection{La fascinación de los personajes}

Otro punto por el que son tan abundantes y exitosas las películas sobre psicópatas es por la fascinación que estos personajes despiertan en el espectador. Una fascinación que se vertebra sobre dos polos encontrados, las dos caras del psicópata: el seductor y el criminal. Por un lado, nos resultan atractivos porque acostumbran a ser elegantes, su forma de vestirse y de moverse nos atrapa y nos enamora. Pero por otro lado, tienen el poder de convertir en un instante el sonreír galán en una risa de monstruo. Esta fascinación y horror a la vez se ejemplifica perfectamente en una escena de Tesis (Alejandro Amenábar, 1996), en la que la protagonista tiene un sueño. Sueña que Bosco (Eduardo Noriega, asesino que graba sus crímenes para comercializar snuff-movies) la visita en su casa por la noche y se aproxima a su cama con una áurea fantástica. Ella lo desea pero a la vez lo teme. Cuando sus cuerpos están muy cerca, el chico empieza a besarla, pero a la vez vemos como le clava un cuchillo. Es un claro ejemplo del peligro que supone ser seducido/da por un psicópata

La mayor parte de personajes son hombres, interpretados cómo hemos dicho por actores atractivos y reconocidos. Aun cuando son pocos los casos de mujeres psicópatas, no podemos olvidar la Sharon Stone de Instinto Bàsico (Paul Verhoeven 1992), la cual utiliza su belleza para conseguir sus objetivos.

\subsubsection{La fascinación de los personajes.}

Estas películas también se aprovechan de la curiosidad que siente el espectador. Los personajes malvados nos atraen porque queremos saber cómo son, como se comportan en su vida diaria. Intentamos observar su conducta porque nos gustaría entender porque se comportan así, queremos descifrar las pautas de su anormalidad. Estamos atónitos ante el comportamiento violento de los personajes puesto que, objetivamente no tienen ninguna justificación. Como los psicópatas son imposibles de comprender, las películas nos superan y los personajes siempre ganan al espectador. Es muy habitual que al final el asesino quede impune o consiga escaparse (El silencio de los corderos, American Psycho) Incluso, en el caso de American Psycho y Ted 
Bundy, los personajes llegan a confesar sus crímenes a algún amigo y este no se los cree, se piensa que es una broma.

Isabel Santaeularia apunta que "aunque sus actos son inmorales, son personajes que viven según su propia ley y, por lo tanto, son atractivos en tanto y cuánto nos permiten, al menos de forma vicaria, vivir al limite." (Santaeularia, 2009, p 183)

\subsubsection{Violencia}

Son películas muy explícitas con respecto a los medios y las formas que utilizan los psicópatas para asesinar a sus víctimas. Hay muy pocos fuera de campo, todo se muestra en la pantalla, que acaba convirtiéndose en un escaparate de los horrores que estos personajes pueden cometer. La mirada del espectador permanece atenta, la curiosidad no nos deja apartarla. Hasta que al final, muchas imágenes nos acaban hiriendo. Y se comprueba el famoso refrán popular de que muy a menudo es mejor (o peor) la imaginación que no la exhibición de todos los detalles. Esto ya hace referencia al saber hacer de los directores, pero hace falta apuntar que muchas películas utilizan un protagonista psicópata únicamente para permitirse filmar escenas violentas y mostrar todos los detalles de los asesinatos. Caer en esto es desaprovechar el gran número de matices que proporciona la vida diaria y no siempre violenta de un psicópata. Además, no podemos olvidar las consecuencias que la violencia explícita puede provocar. A menudo se acusa a este tipo de películas de hacer apología del asesinato. Desde Aristóteles y Platón son presentes dos teorías: la teoría de la infección o corrupción y la teoría de la catarsis. Según la primera, habría algún tipo de asociación entre la observación de la violencia y el comportamiento agresivo. En cambio, según la segunda, observar violencia supone una clase de purga psicológica o liberación de los sentimientos agresivos que disminuye la conducta agresiva de algunas personas.

Todo esto está todavía por demostrar, puesto que no se ha hecho ningún estudio multidisciplinar. Luis Rojas Marcos, en Las semillas de la violencia, habla de que los efectos de la violencia en televisión y en cine son, de una parte, insensibilidad a la violencia en la vida real y miedo generalizado de la población a encontrarse en situaciones violentas; por otro lado, un aumento de la agresividad en gente que ya es propensa y una catarsis por el resto.

\section{CONCLUSIONES}

Por lo tanto, podríamos concluir que el éxito de los personajes psicópatas como protagonistas en el cine se basa en la conjunción de los factores anteriormente analizados. Con mayor o menor fortuna, las películas utilizan estos elementos ya sea para despertar la curiosidad del público, por atraer a los adolescentes ávidos de violencia o para captar a los seguidores de determinados actores. Lo que está claro es el poder de seducción de los personajes y la fascinación que despiertan en el espectador puesto que en los últimos años han conseguido que el cine sobre psicópatas acontezca un subgénero del thriller, el psico-horror, de gran aceptación 
entre el público.

\section{REFERENCIAS}

Burgess, A. (1976). La naranja mecánica". Barcelona:. Minotauro.

Camus, A. (1949). El extranjero. Barcelona: Círculo de lectores.

Carrère, E. (2000). El adversario. Barcelona: Anagrama

Easton Ellis, B. (1994). American psycho. Barcelona: Ed.B

Garrido, V. (2000). El psicópata. Valencia: Algar Editorial

Losilla, C.(1993). El cine de terror. Barcelona: Paidós Studio.

Pérez, X. \& Balló, J. (1997). La llavor inmortal". Barcelona: Ed. Empúries.

Rojas Marcos, L. (1995). Las semillas de la violencia. Madrid: Espasa Calpe.

Sanchis, V.(1996). Violencia en el cine. Valencia: La Máscara

Santaularia, I.(2009). El monstruo humano. Una introducción a la ficción de los asesinos en serie. Barcelona: Laertes

Shattuck, R. (1998). Conocimiento prohibido. Madrid: Grupo Santillana de Ediciones

\section{Mariona Visa Barbosa}

Tesis Doctoral en curso: "La representació de la infància a través de la fotografia: de l'àlbum fotogràfic a les plataformes digital. Diploma de Estudios Avanzados (DEA), del Doctorado en Comunicación Social de la Universidad Pompeu Fabra, Barcelona 2007 con la Tesina Les vinyetes gràfiques de Jordi Labanda com a discurs sobre noves tendències socials. Personal investigador en la Universitat de Lleida des del curso. Departamento de Comunicación Audiovisual. Miembro del grupo de investigación Preconsolidado de la UDL 'Cultura de Masses Audiovisual i Construcció de les Identitats a la Catalunya Contemporània' 